\title{
Air cloud algorithm for diminution of active power loss
}

\author{
Kanagasabai Lenin \\ Prasad V. Potluri Siddhartha Institute of Technology, India
}

\begin{tabular}{l} 
Article Info \\
\hline Article history: \\
Received Jan 3, 2020 \\
Revised Jan 21, 2020 \\
Accepted Mar 4, 2020 \\
\hline
\end{tabular}

Keywords:

Air cloud

Optimal reactive power

Transmission loss

\begin{abstract}
In this work, air cloud (AC) algorithm is used to solve the optimal reactive power problem. Clouds shape in numerous ways. Convective clouds are created when moist air is warmed and expand into floating. Air raises haulage water vapour and within it expands and gets cooled as it goes. As the temperature and pressure of the air diminish, its saturation point - the equilibrium level of evaporation and condensation - is reduced. Every $\mathrm{x}$ is one cloud droplet, and qualitative characteristic of one cloud is explained by the three digital character (Ex, En, He), droplets number n, where Ex (Expected value), En (Entropy) and He (Hyper entropy) of one cloud determine centre position of cloud, cover range of cloud and thickness of cloud equally. Projected AC algorithm has been tested in standard IEEE 14, 57, 300 bus systems and simulations results show the better performance of the proposed algorithm in reducing the real power loss.
\end{abstract}

This is an open access article under the CC BY-SA license.

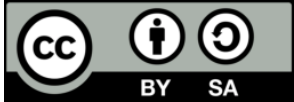

\section{Corresponding Author:}

Kanagasabai Lenin,

Prasad V. Potluri Siddhartha Institute of Technology

Kanuru, Vijayawada, Andhra Pradesh, 520007, India.

Email: gklenin@gmail.com

\section{INTRODUCTION}

Reactive power optimization problem plays main role in secure \& economic operation of the power system. Several conventional methods [1-8] used already for solving the problem. Various drawbacks have been found in the conventional methods and mainly difficulty in handling the inequality constraints. Last two decades many evolutionary algorithms [9-20] has been applied tom solve the problem. In this work air cloud (AC) algorithm has been applied to solve the optimal reactive power problem. Dynamics of cloud development, expansion, motion and dissipation are versatile. In the progress of a cloud simulation, it is significant to realize dynamics so that high-quality estimation can be selected which allow competent implementation without sacrifice realism. AC algorithm is stimulated from the actions of cloud such as formation performance, varying performance and spread out actions of cloud. The whole explore space is alienated into several dislodge regions according to the particular rule, and each region possess with air pressure value and humidity value. Projected AC algorithm has been tested in standard IEEE 14, 57, 300 bus systems and simulations results show the better performance of the proposed algorithm in reducing the real power loss.

\section{PROBLEM FORMULATION}

Objective of the problem is to reduce the true power loss:

$$
\mathrm{F}=\mathrm{P}_{\mathrm{L}}=\sum_{\mathrm{k} \in \mathrm{Nbr}} \mathrm{g}_{\mathrm{k}}\left(\mathrm{V}_{\mathrm{i}}^{2}+\mathrm{V}_{\mathrm{j}}^{2}-2 \mathrm{~V}_{\mathrm{i}} \mathrm{V}_{\mathrm{j}} \cos \theta_{\mathrm{ij}}\right)
$$


Voltage deviation given as follows:

$$
\mathrm{F}=\mathrm{P}_{\mathrm{L}}+\omega_{\mathrm{v}} \times \text { Voltage Deviation }
$$

Voltage deviation given by:

$$
\text { Voltage Deviation }=\sum_{i=1}^{N p q}\left|V_{i}-1\right|
$$

Constraint (Equality)

$$
\mathrm{P}_{\mathrm{G}}=\mathrm{P}_{\mathrm{D}}+\mathrm{P}_{\mathrm{L}}
$$

Constraints (Inequality)

$$
\begin{aligned}
& \mathrm{P}_{\text {gslack }}^{\min } \leq \mathrm{P}_{\text {gslack }} \leq \mathrm{P}_{\text {gslack }}^{\text {max }} \\
& \mathrm{Q}_{\mathrm{gi}}^{\min } \leq \mathrm{Q}_{\mathrm{gi}} \leq \mathrm{Q}_{\mathrm{gi}}^{\mathrm{max}}, \mathrm{i} \in \mathrm{N}_{\mathrm{g}} \\
& \mathrm{V}_{\mathrm{i}}^{\min } \leq \mathrm{V}_{\mathrm{i}} \leq \mathrm{V}_{\mathrm{i}}^{\max }, \mathrm{i} \in \mathrm{N} \\
& \mathrm{T}_{\mathrm{i}}^{\min } \leq \mathrm{T}_{\mathrm{i}} \leq \mathrm{T}_{\mathrm{i}}^{\text {max }}, \mathrm{i} \in \mathrm{N}_{\mathrm{T}} \\
& \mathrm{Q}_{\mathrm{c}}^{\min } \leq \mathrm{Q}_{\mathrm{c}} \leq \mathrm{Q}_{\mathrm{C}}^{\max }, \mathrm{i} \in \mathrm{N}_{\mathrm{C}}
\end{aligned}
$$

\section{AIR CLOUD ALGORITHM}

AC algorithm is stimulated from the actions of cloud such as formation performance, varying performance and spread out actions of cloud. The whole explore space is alienated into several dislodge regions according to the particular rule, and each region possess with air pressure value and humidity value. Clouds are able to be engendered in regions with dampness value are superior to precise threshold. Underneath the venture of wind, clouds shift from regions with superior air pressure value towards lower air pressure value regions. In the movement procedure, the droplets of one cloud would expand or get hold of joint action according to the air pressure difference.

Presume that $U$ is the space; the region is defined as subspace after the separation of $U$ according to various systems and dimension of $\mathrm{U}$ is alienated into $\mathrm{M}$ minute hiatus

$$
I_{i}=\frac{\left(u_{i}-l_{i}\right)}{M}, i=1,2, \ldots, D
$$

Entire search space split into MD regions, which meet up the subsequent property:

$$
\left\{\begin{array}{c}
\bigcup_{i=1}^{M^{D}} U_{i}=U \\
U_{i} \cap U_{j}=\emptyset, \forall i, j \in\left\{1,2, \ldots, M^{D}\right\}, I \neq j
\end{array}\right.
$$

In $\mathrm{U}$ Cloud $\mathrm{C}$ is defined as a qualitative observation, and $\mathrm{x}$ is the stochastic implementation of $\mathrm{C}, \mathrm{x} \in \mathrm{U}$. Every $\mathrm{x}$ is one cloud droplet, and qualitative characteristic of one cloud is explained by the three digital character (Ex, En, He), droplets number n, where Ex (Expected value), En (Entropy) and He (Hyper-entropy) of one cloud determine centre position of cloud, cover range of cloud and thickness of cloud equally.

Assume m clouds in iteration $\mathrm{t}$, then:

$$
\mathrm{C}^{\mathrm{t}}=\left\{\mathrm{C}_{1}^{\mathrm{t}}, \mathrm{C}_{2}^{\mathrm{t}}, \ldots, \mathrm{C}_{\mathrm{j}}^{\mathrm{t}}, \ldots, \mathrm{C}_{\mathrm{m}}^{\mathrm{t}}\right\}
$$


Clouds droplets numbers,

$$
n^{t}=\left\{n_{1}^{t}, n_{2}^{t}, \ldots, n_{j}^{t}, \ldots, n_{m}^{t}\right\}
$$

All clouds droplets numbers,

$$
\begin{aligned}
& \left\{\begin{array}{l}
\mathrm{n}_{\mathrm{j}}>d N, \forall j=1,2, \ldots, m \\
\sum_{\mathrm{j}=1}^{\mathrm{m}} \mathrm{n}_{\mathrm{j}} \leq \mathrm{N}
\end{array}\right. \\
& \mathrm{C}(\mathrm{x}) \sim \mathrm{N}\left(\mathrm{C} \cdot \mathrm{Ex}, \mathrm{En}^{\prime 2}\right)
\end{aligned}
$$

Dampness value of the region is,

$$
\mathrm{X}_{\mathrm{i}}^{*}=\underset{\mathrm{x} \in \mathrm{U}_{\mathrm{i}}}{\arg \max \mathrm{f}(\mathrm{x}), \mathrm{H}_{\mathrm{i}} \mathrm{f}\left(\mathrm{X}_{\mathrm{i}}^{*}\right)}
$$

Air pressure value is:

$$
\begin{aligned}
& \mathrm{P}_{\mathrm{i}}=\operatorname{CNT}\left(\mathrm{x} \in \mathrm{U}_{\mathrm{i}}\right), \mathrm{i}=1,2, \ldots, \mathrm{M}^{\mathrm{D}} \\
& \mathrm{Ht}=\mathrm{H}_{\text {min }}+\lambda^{*}\left(\mathrm{H}_{\text {max }}-\mathrm{H}_{\text {min }}\right)
\end{aligned}
$$

Creation of cloud regions as

$$
\mathrm{R}=\left\{\mathrm{i} \mid \mathrm{H}_{\mathrm{i}}>H t, i=1,2, \ldots, \mathrm{M}^{\mathrm{D}}\right\}
$$

Preliminary entropy value EnMo found by,

$$
\begin{aligned}
\text { EnMo } & =\frac{\mathrm{I} / \mathrm{M}}{\mathrm{A}} \\
\mathrm{EnM}^{\mathrm{t}} & =\mathrm{EnM}^{0} \times \xi
\end{aligned}
$$

Total number of droplets recently generated in existing iteration is found by

$$
n N e w=N-\sum_{j=1}^{m} n_{j}^{t}
$$

Assume $\mathrm{R}=\left\{\mathrm{i} \mid \mathrm{H}_{\mathrm{i}}>H t, i=1,2, \ldots, \mathrm{M}^{\mathrm{D}}\right\}$ has $\mathrm{k}$ elements, the clouds recently engendered are, $\mathrm{C}_{\mathrm{m}+1}^{\mathrm{t}} . \mathrm{C}_{\mathrm{m}+2}^{\mathrm{t}}, \ldots, \mathrm{C}_{\mathrm{m}+\mathrm{j}}^{\mathrm{t}}, \ldots, \mathrm{C}_{\mathrm{m}+\mathrm{k}}^{\mathrm{t}}$. Then the droplets number of cloud newly generated has a relative relation with the humidity of regions $[21,22]$ in $\mathrm{R}$, is given by,

$$
\mathrm{n}_{\mathrm{m}+\mathrm{j}}^{\mathrm{t}}=\frac{\mathrm{H}_{\mathrm{R}(\mathrm{j})}}{\sum_{\mathrm{j}=1}^{\mathrm{k}} \mathrm{H}_{\mathrm{R}(\mathrm{j})}} \times \mathrm{nNew}
$$

Recently generated of clouds features are described as,

$$
\mathrm{C}_{\mathrm{m}+\mathrm{j}}^{\mathrm{t}} \cdot \mathrm{Ex}=\mathrm{X}_{\mathrm{s}(\mathrm{j})}^{*}, \mathrm{C}_{\mathrm{m}+\mathrm{j}}^{\mathrm{t}} \cdot \mathrm{En}=\mathrm{EnM}^{\mathrm{t}}, \mathrm{C}_{\mathrm{m}+\mathrm{j}}^{\mathrm{t}} \cdot \mathrm{He}=\mathrm{He}, 0<j \leq k .
$$

Presume the region where the cloud $c_{j}^{t}(j=1,2, \ldots, m)$ positioned is designated as US, and then arbitrarily pick one region of air pressure value is inferior than $\mathrm{U}_{\mathrm{S}}^{\prime} \mathrm{s}$ as the objective region UT, then differentiation of pressure between US and UT is found by $\Delta \mathrm{P}=\mathrm{P}_{\mathrm{S}}-\mathrm{P}_{\mathrm{T}}$. Modernized equation of cloud's location is found by: 


$$
\mathrm{C}_{\mathrm{j}}^{\mathrm{t}+1} \cdot \mathrm{Ex}=\mathrm{C}_{\mathrm{j}}^{\mathrm{t}} \cdot \mathrm{Ex}+\overrightarrow{\mathrm{V}}_{\mathrm{j}}^{\mathrm{t}+1}, 0<j \leq m
$$

Altering velocity of cloud is found by,

$$
\begin{aligned}
& \overrightarrow{\mathrm{V}}_{\mathrm{j}}^{\mathrm{t}+1}=\overrightarrow{\mathrm{e}} \times 6 \times \mathrm{C}_{\mathrm{j}}^{\mathrm{t}} \cdot \mathrm{En} \\
& \overrightarrow{\mathrm{e}}=\frac{(1-\beta) \times \overrightarrow{\mathrm{V}}_{\mathrm{j}}^{\mathrm{t}}+\beta \times\left(\mathrm{X}_{\mathrm{T}}^{*}-\mathrm{C}_{\mathrm{j}}^{\mathrm{t}} \cdot \mathrm{Ex}\right)}{\left\|(1-\beta) \times \overrightarrow{\mathrm{V}}_{\mathrm{j}}^{\mathrm{t}}+\beta \times\left(\mathrm{X}_{\mathrm{T}}^{*}-\mathrm{C}_{\mathrm{j}}^{\mathrm{t}} \cdot \mathrm{Ex}\right)\right\|} \\
& \beta=\frac{\Delta \mathrm{p}}{\mathrm{P}_{\text {max }}-\mathrm{p}_{\text {min }}}
\end{aligned}
$$

$\mathrm{B}$ indicates the persuading degree of air pressure with the fitness value of $\mathrm{X}_{\mathrm{T}}^{*}$ specify the humidity value within the region UT . Owing to the vanishing or have a collision between clouds in the shift process power of cloud get diminish, so weaken rate $\gamma$, is added as $\gamma \times 100 \%$ after each iteration. Modernized droplets number is found by:

$$
\mathrm{n}_{\mathrm{j}}^{\mathrm{t}+1}=\mathrm{n}_{\mathrm{j}}^{\mathrm{t}} \times(1-\gamma) 0<j \leq m
$$

When droplets are a lesser amount to $\mathrm{dN}$ subsequent step, it is considered as deteriorated. $\gamma$ is primarily used to verify the speed of clouds, which movedand the value considered as $\gamma=0.190$. Assume the region where the cloud $c_{j}^{\mathrm{t}}(\mathrm{j}=1,2, \ldots, \mathrm{m})$ situated is US, and when UT $\neq$ US, the expanded fleetness of cloud is articulated as:

$$
\mathrm{C}_{\mathrm{j}}^{\mathrm{t}+1} \cdot \mathrm{En}=\mathrm{C}_{\mathrm{j}}^{\mathrm{t}} \cdot \mathrm{En} \times(1+\alpha)
$$

$\alpha$ is expand factorand computed by,

$$
\alpha=\frac{\Delta \mathrm{P}}{\mathrm{P}_{\max }}
$$

Pmax is the greatest air pressure difference in the search space; $\Delta \mathrm{P}=\mathrm{P}_{\mathrm{S}}-\mathrm{P}_{\mathrm{T}}$ is the pressure difference between US and UT. When UT $=U S$, the cloudC $\mathrm{j}_{\mathrm{j}}^{\mathrm{t}}$ will expand according to the maximum pressure with difference between US and peripheral regions, the dampness values, air pressure values of all regions is updated every time subsequent to the making process of cloud, the cloud's alter procedure and expand progression.

a. Initialization of the procedure

b. creation of Clouds

c. modernize Humidity Value, Air Pressure value of area

d. alter behaviour of Cloud is computed

e. expand Behaviour of Cloud is computed

f. modernize Humidity Value, Air Pressure Value of area

g. if End of Loop, thenstop or elsemove to Step c

\section{SIMULATION RESULTS}

At first in standard IEEE 14 bus system the validity of the proposed algorithm has been tested and comparison results are presented in Table 1 (using [23]). Real power loss has been considerably reduced and vital parameters are within the limits. Then the performance of the projected algorithm has been validated by tested in standard IEEE 57 bus system [24]. Total active and reactive power demands in the system are 1248.23 MW and 334.16 MVAR. Generator data the system is given in Table 2. The optimum loss comparison (of [25-28]) is presented in Table 3. Then the performance of the proposed algorithm has been tested in standard IEEE 300 bus system [24]. Table 4 shows the comparison [28, 29] of real power loss obtained after optimization. 
Table 1. Comparison of real power loss

\begin{tabular}{cccc}
\hline Control variables & $\mathrm{ABCO}[23]$ & $\mathrm{IABCO}[23]$ & $\mathrm{AC}$ \\
\hline V1 & 1.06 & 1.05 & 1.04 \\
V2 & 1.03 & 1.05 & 1.03 \\
V3 & 0.98 & 1.03 & 1.04 \\
V6 & 1.05 & 1.05 & 1.01 \\
V8 & 1.00 & 1.04 & 0.90 \\
Q9 & 0.139 & 0.132 & 0.100 \\
T56 & 0.979 & 0.960 & 0.900 \\
T47 & 0.950 & 0.950 & 0.900 \\
T49 & 1.014 & 1.007 & 1.000 \\
Ploss (MW) & 5.92892 & 5.50031 & 4.10028 \\
\hline
\end{tabular}

Table 2. Generator data

\begin{tabular}{ccccc}
\hline $\begin{array}{c}\text { Generator } \\
\text { No }\end{array}$ & $\begin{array}{c}\text { Pgi } \\
\text { minimum }\end{array}$ & $\begin{array}{c}\text { Pgi } \\
\text { maximum }\end{array}$ & $\begin{array}{c}\text { Qgi } \\
\text { minimum }\end{array}$ & $\begin{array}{c}\text { Qgi } \\
\text { maximum }\end{array}$ \\
\hline 1 & 25.00 & 50.00 & 0.00 & 0.00 \\
2 & 15.00 & 90.00 & -17.00 & 50.00 \\
3 & 10.00 & 500.00 & -10.00 & 60.00 \\
4 & 10.00 & 50.00 & -8.00 & 25.00 \\
5 & 12.00 & 50.00 & -140.00 & 200.00 \\
6 & 10.00 & 360.00 & -3.00 & 9.00 \\
7 & 50.00 & 550.00 & -50.00 & 155.00 \\
\hline
\end{tabular}

Table 3. Comparison of losses

\begin{tabular}{ccccccccc}
\hline Parameter & CLPSO[26] & DE[25] & GSA[25] & OGSA[27] & SOA[26] & QODE[25] & CSA[28] & AC \\
\hline PLOSS (MW) & 24.5152 & 16.7857 & 23.4611 & 23.43 & 24.2654 & 15.8473 & 15.5149 & 12.1052 \\
\hline
\end{tabular}

Table 4. Comparison of real power loss

\begin{tabular}{ccccc}
\hline Parameter & EGA [29] & EEA [29] & CSA [28] & AC \\
\hline PLOSS $(\mathrm{MW})$ & 646.2998 & 650.6027 & 635.8942 & 622.0024 \\
\hline
\end{tabular}

\section{CONCLUSION}

In this work, AC algorithm successfully solved the optimal reactive power problem. Actions of cloud such as formation performance, varying performance and spread out actions of cloud are modeled. In the movement procedure, the droplets of one cloud would expand or get hold of joint action according to the air pressure difference. Projected AC algorithm has been tested in standard IEEE 14, 57, 300 bus systems and simulations results show the better performance of the proposed algorithm in reducing the real power loss.

\section{REFERENCES}

[1] O. Alsac and B. Stott, "Optimal Load Flow with Steady-State Security," IEEE Transactions on Power Apparatus and Systems, vol. PAS-93, no. 3, pp. 745-751, 1974.

[2] K. Y. Lee, Y. M. Park, and J. L. Ortiz, "A United Approach to Optimal Real and Reactive Power Dispatch," IEEE Transactions on Power Apparatus and Systems, vol. PAS-104, no. 5, pp. 1147-1153, 1985.

[3] A. Monticelli, M. V. F. Pereira, and S. Granville, "Security-Constrained Optimal Power Flow with Post-Contingency Corrective Rescheduling," IEEE Transactions on Power Systems, vol. 2, no. 1, pp. 175-180, 1987.

[4] N. Deeb and S. M. Shahidehpour, "Linear reactive power optimization in a large power network using the decomposition approach," IEEE Transactions on Power Systems, vol. 5, no. 2, pp. 428-438, 1990.

[5] E. Hcbson, "Network Constrained Reactive Power Control Using Linear Programming," IEEE Transactions on Power Apparatus and Systems, vol. PAS-99, no. 3, pp. 868-877, 1980.

[6] K. Y. Lee, Y. M. Park, and J. L. Ortiz, "Fuel-cost minimisation for both real-and reactive-power dispatches," IEE Proceedings C (Generation, Transmission and Distribution), vol. 131, no. 3, 1984.

[7] M. K. Mangoli, K. Y. Lee, and Y. M. Park, "Optimal real and reactive power control using linear programming,” Electric Power Systems Research, vol. 26, no. 1, pp. 1-10, 1993.

[8] C. A. Canizares, A. C. Z. De Souza and V. H. Quintana, "Comparison of performance indices for detection of proximity to voltage collapse," IEEE Transactions on Power Systems, vol. 11, no. 3, pp. 1441-1450, 1996.

[9] A. Berizzi, et al., " A GA approach to compare orpf objective functions including secondary voltage regulation," Electric Power Systems Research, vol. 84, no. 1, pp. 187-194, 2012.

[10] P. Roy, S.Ghoshal, and S.Thakur," Optimal var control for improvements in voltage profiles and for real power loss minimization using biogeography based optimization," International Journal ofElectrical Power and Energy Systems, vol. 43, no. 1, pp. 830-838, 2012.

[11] Z. Hu, X.Wang, and G.Taylor, "Stochastic optimal reactive power dispatch: Formulation and solution method," International Journal of Electrical Power and Energy Systems, vol. 32, no. 6, pp. 615-621, 2010.

[12] A. Mukherjee and V. Mukherjee, "Solution of optimal reactive power dispatch by chaotic krill herd algorithm," IET Generation, Transmission \& Distribution, vol. 9, no. 15, pp. 2351-2362, 2015.

[13] Z. Hu, X. Wang, and G. Taylor, "Stochastic optimal reactive power dispatch: Formulation and solution method," Electr. Power Energy Syst., vol. 32, no. 6, pp. 615-621, 2010, doi: 10.1016/j.ijepes.2009.11.018 
[14] M. Morgan, et al., "Multi-Objective Evolutionary Programming (MOEP) Using Mutation Based on Adaptive Mutation Operator (AMO) Applied For Optimal Reactive Power Dispatch," ARPN Journal of Engineering and Applied Sciences, vol. 11, no. 14, pp. 8884-8888, 2016.

[15] K. Pandiarajan and C. Babulal, "Fuzzy harmony search algorithm based optimal power flow for power system security enhancement," International Journal of Electrical Power \& Energy Systems, vol. 78, pp. 72-79, 2016.

[16] M. Morgan, et al., "Benchmark Studies on Optimal Reactive Power Dispatch (ORPD) Based Multi-objective Evolutionary Programming (MOEP) Using Mutation Based on Adaptive Mutation Adapter (AMO) and Polynomial Mutation Operator (PMO)," Journal of Electrical Systems, vol. 12, no. 1, pp. 121-132, 2016.

[17] R. N. S. Mei, M. H. Sulaiman, and Z. Mustaffa, "Ant Lion Optimizer for Optimal Reactive Power Dispatch Solution,” Journal of Electrical Systems, no. Special Issue AMPE2015, pp. 68-74, 2016.

[18] A. Gagliano and F. Nocera, "Analysis of the performances of electric energy storage in residential applications," International Journal of Heat and Technology, vol. 35, no. Special Issue1, pp. S41-S48, 2017, doi: 10.18280/ijht.35Sp0106.

[19] M. Caldera, P. Ungaro, G. Cammarata, and G. Puglisi, "Survey-based analysis of the electrical energy demand in Italian households," Mathematical Modelling of Engineering Problems, vol. 5, no. 3, pp. 217-224, 2018, doi: 10.18280/mmep.050313

[20] L. Zajmi, F. Y. Ahmed, and A. A. Jaharadak, "Concepts, Methods, and Performances of Particle Swarm Optimization, Backpropagation, and Neural Networks," Applied Computational Intelligence and Soft Computing, vol.2018, 2018, doi: 10.1155/2018/9547212.

[21] M. J. Harris, et al., "Simulation of Cloud Dynamics on Graphics Hardware," in Proc. ACM SIGGRAPH/EUROGRAPHICS Conf. Graphics Hardware, San Diego, 2003) pp. 92-101.

[22] D.-Y Li and C.-Y. Liu, "Study on the universality of the normal cloud model," Engineering Science, vol. 6, no. 8, pp. 28-34, 2004.

[23] C. M. K. Sivalingam, S. Ramachandran, and P. S. S. Rajamani, "Reactive power optimization in a power system network through metaheuristic algorithms," Turkish Journal of Electrical Engineering \& Computer Sciences, vol. 25, no. 6, pp. 4615-4623, 2017, doi:10.3906/elk-1703-159.

[24] http://www2.ee.washington.edu/research/pstca/.

[25] M. Basu, "Quasi-oppositional differential evolution for optimal reactive power dispatch," International Journal of Electrical Power \& Energy Systems, vol. 78, pp. 29-40, 2016.

[26] C. Dai, et al., "Seeker Optimization Algorithm for Optimal Reactive Power Dispatch," IEEE Transactions on Power Systems, vol. 24, no. 3, pp. 1218-1231, 2009.

[27] X.-S. Yang, "Firefly Algorithm, Lévy Flights and Global Optimization," Research and Development in Intelligent Systems XXVI, pp. 209-218, 2009.

[28] S. R. Salkuti, "Optimal Reactive Power Scheduling Using Cuckoo Search Algorithm," International Journal of Electrical and Computer Engineering (IJECE), vol. 7, no. 5, pp. 2349-2356, 2017.

[29] S. S. Reddy, et al., "Faster evolutionary algorithm based optimal power flow using incremental variables," International Journal of Electrical Power \& Energy Systems, vol. 54, pp. 198-210, 2014. 